\title{
Measurement of the PMSM Shaft Position with An Absolute Encoder
}

\author{
Tomasz Rudnicki (D)
}

Institute of Electronics, Faculty of Automatic Control, Electronics and Computer Science, Silesian University of Technology, 44-100 Gliwice, Poland; tomasz.rudnicki@polsl.pl

Received: 7 September 2019; Accepted: 25 October 2019; Published: 27 October 2019

\begin{abstract}
The most critical aspect of assessing a permanent magnet synchronous motor is the problem of correctly measuring the position of the synchronous motor shaft. The purpose of this article was to show the effects of employing an absolute encoder to control a synchronous motor with permanent magnets while encountering disturbances. This problem is often overlooked, but it appears from time to time. The correct measurement of the shaft position eliminates improper motor operation characterized by jerking. The article showed that despite momentary erroneous readings of the shaft's position, it was still possible to control the permanent magnet synchronous motor (PMSM). This also allows for correct measurement of the motor speed. This paper originally proposed an adaptive correction method for a rotary encoder.
\end{abstract}

Keywords: absolute position; encoder; permanent magnet synchronous motor; power unit; pulse width modulation (PWM); rotary sensor

\section{Introduction}

Recent advances in car design have been driven, in part, by the dynamic development of electric drives. The most promising advance in this respect seems to be the permanent magnet synchronous motor (PMSM) due to its low weight, small size, high efficiency, and high torque. Electric motors with permanent magnets $\mathrm{NdFeB} \mathrm{[1]} \mathrm{simplify} \mathrm{the} \mathrm{motor} \mathrm{structure.} \mathrm{The} \mathrm{motor} \mathrm{stator} \mathrm{is} \mathrm{usually} \mathrm{similar} \mathrm{to} \mathrm{the}$ stator of induction motors and the rotor contains permanent magnets. The magnets and the armature winding are positioned so that the electromotive force (EMF) generated as a result of rotation is sinusoidal. A characteristic feature of PMSM motors is a wide range of speed control [1-3]. Permanent magnet motors lack commutators, so the weight of the drive design is significantly transferred toward the electronic control of the electric motor. Motors with permanent magnets demonstrate high efficiency, high torque, and low weight, all of which are highly important for vehicle design.

In order to obtain a smooth regulation of the rotational speed of the drive system with a PMSM, the angle of the motor shaft must be measured correctly. Errors in the measurement of the shaft angle cause unstable operation of the motor, jerking, or excessive current consumption, which can even damage the PMSM. Therefore, it is very important that the position measured by the encoder is correct. Unfortunately, the encoder works in conditions of strong interference, which means the central unit must check and correct the measured position by the encoder at all times. This allows for smooth speed control and stable operation of the PMSM. Detection of information loss error for the incremental encoder was presented in [4]. There are also methods of sensor less control of the PMSM, but due to the high precision of the control, the article focused on the control system using an absolute encoder [5,6]. In conventional position sensorless permanent magnet (PM) machine drives, the rotor position is obtained from the phase-locked loop (PLL) with the regulation of spatial signal in estimated back electromotive force (EMF) voltages. Due to the sinusoidal distribution of back-EMF voltages, a small-signal approximation is assumed in the PLL in order to estimate the position [7-11]. In the 
sensorless control method, the stator current is measured to estimate the speed of the motor. When the PMSM sensorless control is used in an electric vehicle, it sometimes causes another problem. When the motor is running in steady state and is suddenly given a large load that has reverse torque direction, a problem will arise [12-14]. Therefore, an original method was proposed that obtained good results when the PMSM is operating in such adverse conditions.

\section{Control Unit for PMSM}

One of the typical PMSM motor control systems is field oriented control (FOC), the idea of which is presented in Figure 1 [15].

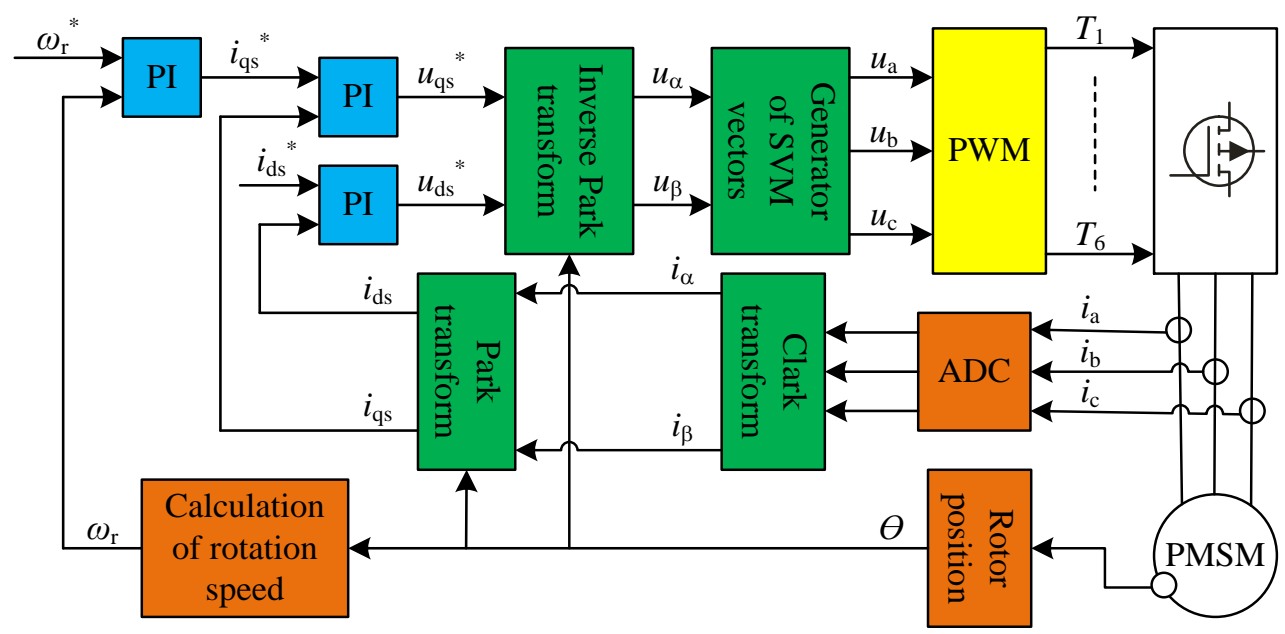

Figure 1. Diagram of signal flows for a permanent magnet synchronous motor (PMSM).

In order to enable fast calculations, the control was performed in a dq-axis rotating system. Two transforms were carried out. First, a three-phase stationary system was converted into a stationary two-axis reference frame. The second transform consisted in the rotation of the foregoing two-axis reference system. Those transforms, respectively referred to as Clarke and Park transforms, enabled substitution of three analog converter (AC) parameters by two digital converter (DC) parameters. As a result, calculations for these two DC signals were much simpler and enabled the subsequent inverse transform to recover the actual three-phase AC results. The signal path (d) refers to magnetic flux, while the signal path $(\mathrm{q})$ is related to torque.

The importance of the feedback for PMSM control provides the current, voltage, and angle of rotation. With appropriate scaling of the signals $\left(i_{\mathrm{a}}, i_{\mathrm{b}}\right.$, and $\left.i_{\mathrm{c}}\right)$ in the analog-to-digital converter (ADC), a Clarke transformation with rotating coordinate system $(d, q)$ was performed to generate the two-phase system $\left(i_{\mathrm{a}}, i_{\mathrm{b}}\right)$. As a result of these calculations, currents $\left(i_{\mathrm{ds}}, i_{\mathrm{qs}}\right)$ were obtained. In the next step, the currents $\left(i_{\mathrm{ds}}, i_{\mathrm{qs}}\right)$ and $\left(i_{\mathrm{ds}}{ }^{*}, i_{\mathrm{qs}}{ }^{*}\right)$ were served on proportional integral (PI) controllers that set new values of the voltages $\left(u_{\mathrm{qs}}{ }^{*}, u_{\mathrm{ds}}{ }^{*}\right)$. Values of these voltages were subjected to the inverse Park transform (using the information on the rotor position $\theta$ ), which produced a voltage $\left(u_{\alpha}, u_{\beta}\right)$. Based on this, the voltages $\left(u_{\mathrm{a}}, u_{\mathrm{b}}, u_{\mathrm{c}}\right)$ were generated. The respective rectangular waveforms for controlling the power transistors $T_{1}-T_{6}$ of the inverter were produced by the pulse width modulation (PWM) block. The $\theta$ was position angle of the rotor [16-18]. The power unit produced a voltage three-phase inverter with an amplitude and offset $[19,20]$. The equations for Clarke and Park transformations are presented in Equation (1) and Equation (2), respectively:

$$
\left[\begin{array}{l}
i_{\alpha} \\
i_{\beta}
\end{array}\right]=\left[\begin{array}{ccc}
1 & -\frac{1}{2} & -\frac{1}{2} \\
0 & \frac{\sqrt{3}}{2} & -\frac{\sqrt{3}}{2}
\end{array}\right]\left[\begin{array}{l}
i_{\mathrm{a}} \\
i_{\mathrm{b}} \\
i_{\mathrm{c}}
\end{array}\right]
$$




$$
\left[\begin{array}{l}
i_{\mathrm{sd}} \\
i_{\mathrm{sq}}
\end{array}\right]=\left[\begin{array}{cc}
\cos (\Theta) & \sin (\Theta) \\
-\sin (\Theta) & \cos (\Theta)
\end{array}\right]\left[\begin{array}{c}
i_{\alpha} \\
i_{\beta}
\end{array}\right]
$$

The equations for inverse Clarke transformation are presented in Equation (3):

$$
\left[\begin{array}{l}
u_{\alpha} \\
u_{\beta}
\end{array}\right]=\left[\begin{array}{cc}
\cos (\Theta) & -\sin (\Theta) \\
\sin (\Theta) & \cos (\Theta)
\end{array}\right]\left[\begin{array}{l}
u_{\mathrm{ds}} \\
u_{\mathrm{qs}}
\end{array}\right]
$$

The transform from the stationary $\alpha \beta$-axis frame to the stationary three-axis, three-phase reference frame of the stator is presented in Equation (4):

$$
\left[\begin{array}{c}
u_{\mathrm{a}} \\
u_{\mathrm{b}} \\
u_{\mathrm{c}}
\end{array}\right]=\left[\begin{array}{cc}
1 & 0 \\
-\frac{1}{2} & \frac{\sqrt{3}}{2} \\
-\frac{1}{2} & -\frac{\sqrt{3}}{2}
\end{array}\right]\left[\begin{array}{l}
u_{\alpha} \\
u_{\beta}
\end{array}\right]
$$

Requirements for the central unit:

- Performing complex mathematical calculations;

- $\quad$ high computing performance;

- $\quad$ appropriate hardware resources, e.g., input/output (I/O) ports, counters, PWM modulator, ADC, serial bus;

- dedication to control three-phase motors.

One of the systems that meets these requirements is the TMS320F2812 signal processor. This processor is a dedicated system for controlling three-phase motors [21].

The MAB28 (Megatron, Munich, Germany) absolute encoder was used for experimental research, which has the following properties:

- Small dimensions;

- 12-bit resolution;

- $\quad+5$ V supply voltage;

- $\quad$ electrically erasable programmable read-only memory (EEPROM);

- $\quad$ serial bus.

Figure 2 shows how to connect the MAB28 encoder to the TMS320F2812 signal processor [22].

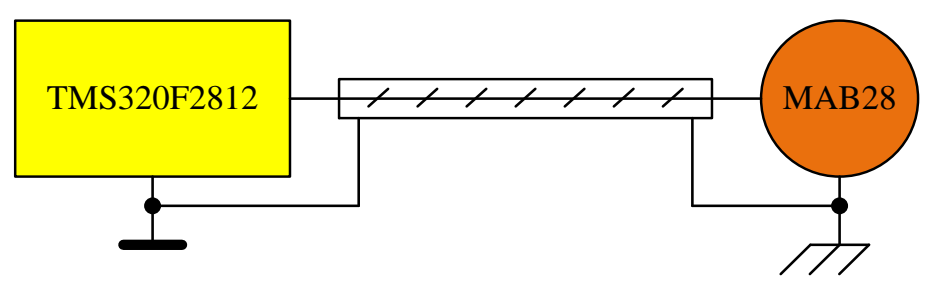

Figure 2. Connecting the MAB28 encoder to the TMS320F2812 signal processor.

The motor speed measurement consists of:

- Reading in the fixed time interval $t_{\mathrm{rpm}}$ of two motor shaft positions (position 1, position $_{2}$ );

- calculation of the obtained geometric angle increment in time unit per rotational speed. 
The calculation of the rotational speed $\omega_{\text {rpm }}$ (in revolutions per minute) was based on the equation (Equation (5)):

$$
\omega_{\mathrm{rpm}}=\frac{\text { position }_{1}-\text { position }_{2}}{2^{12}} \cdot \frac{60}{t_{\mathrm{rpm}}}
$$

Division by $2^{12}$ (4096) was required because the MAB28 encoder has 12-bit resolution. The position 1 and position 2 took values from 0 to 4095 .

The shield of the cable from the signal processor side was connected to the digital ground, while the shield from the encoder side was connected to the metal enclosure of the encoder. The encoder housing was also connected to the metal enclosure of the PMSM. The author's experience shows that if there is no connection between the metal enclosure of the encoder and the digital ground, the number of incorrect encoder readings increases rapidly. Connecting the encoder with a shielded cable reduced the frequency of incorrect readings of the encoder position, but did not completely eliminate them. The incorrect operation of the encoder is shown in Figure 3.

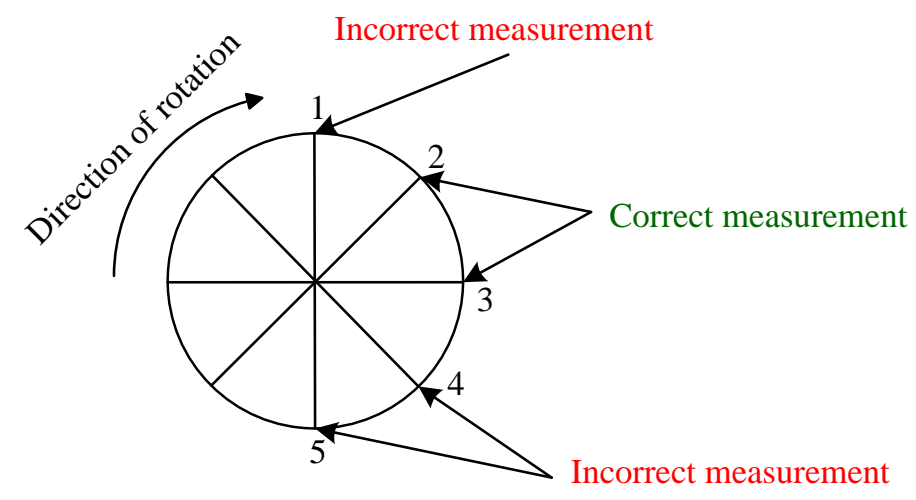

Figure 3. Incorrect operation of the encoder.

The measurements with numbers 1,4 , and 5 were incorrect, while measurements with numbers 2 and 3 were correct. The incorrect measurement of the shaft position results in miscalculation of the shaft position angle. This, in turn, causes motor malfunction manifested by a temporary increase in current consumption by the motor and adversely impacts motor performance. The complete elimination of erroneous readings of the encoder position can take place on the program path. Equation (6) shows how to calculate the shaft position angle $\Theta$ for a 12-bit MAB28 encoder:

$$
\Theta=\frac{\text { position }}{2^{12}} \cdot 360
$$

The programmed elimination of erroneous readings of the encoder position should be adapted to the maximum motor speed. Suppose that the motor has a maximum speed of $\omega_{\max }=3000 \mathrm{rpm}$. Thus, the time of one turn was obtained by Equation (7):

$$
t_{\mathrm{rpm}}=\frac{60}{\omega_{\max }}=20 \mathrm{~ms}
$$

The motor was controlled by the PWM with the frequency of $8 \mathrm{kHz}$, so the interruption from the PWM module was made every $t_{\mathrm{PWM}}=125 \mu \mathrm{s}$. Therefore, information about the angle of the shaft position can be taken at $t_{\mathrm{enc}}=40 \mu \mathrm{s}$ (Figure 4). 


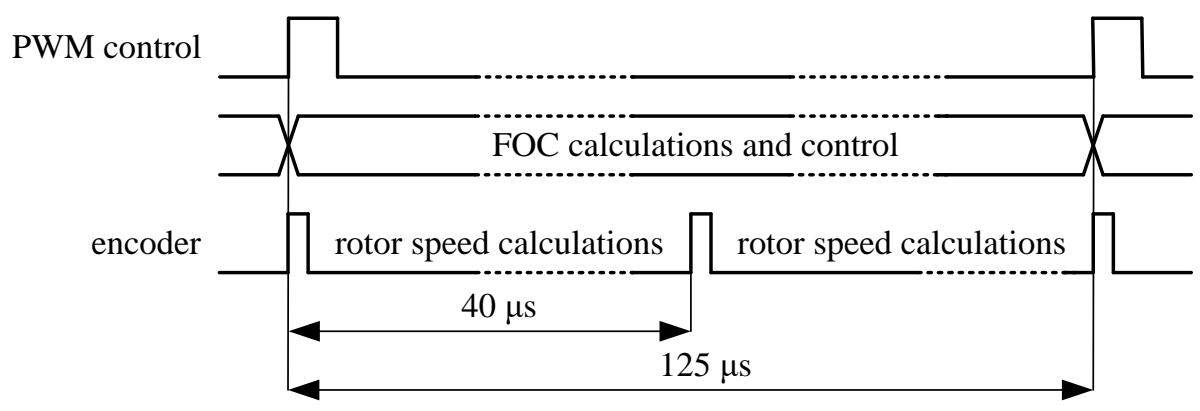

Figure 4. Time dependencies for the encoder and PWM module.

The number of measurements of the angle of the shaft position for the maximum speed $\omega_{\max }=3000 \mathrm{rpm}$ was calculated by Equation (8):

$$
n o_{\Theta}=\frac{t_{\mathrm{rpm}}}{t_{\mathrm{enc}}}=500
$$

or, for the maximum speed of the motor and the encoder reading at $t_{\mathrm{enc}}=40 \mu \mathrm{s}$, the increment of the shaft position angle by Equation (9) was obtained:

$$
\Delta \Theta=\frac{t_{\text {enc }}}{t_{\text {rpm }}} \cdot 360=0.72^{\circ}
$$

In the case of a 12-bit encoder and an angle change of $\Delta \Theta=0.72^{\circ}$, the increment of the encoder value by Equation (10) was obtained:

$$
\Delta \text { position }=\frac{2^{12} \cdot \Delta \Theta}{360}=8
$$

Equation (9) can be determined for the correct measurement of the angle of the motor shaft position. The current position of the encoder $\left(\right.$ position $\left._{\mathrm{i}}\right)$ reading was correct when:

$$
\text { sposition }=\mid \text { position }_{\mathrm{i}}-\text { position }_{\mathrm{i}-1} \mid \leq 8
$$

The time $t_{\mathrm{rpm}}$ changes as the speed changes, so a different angle $\Delta \Theta$ increase was obtained. Calculating the correct position of the encoder in the event of an erroneous reading is a serious problem. An algorithm was proposed in which the increment of the encoder value $\left(\Delta\right.$ position $\left._{\text {new }}\right)$ is calculated on an ongoing basis, and the information on the previous increment of the encoder value $\left(\Delta\right.$ position $\left._{\text {old }}\right)$ is additionally stored. If the "new" increment of the encoder value does not satisfy the Equation (11), then the correct value of the encoder position needs to be determined. This can be calculated from Equation (12):

$$
\text { position }_{\mathrm{i}}=\text { position }_{\mathrm{i}-1}+\text { position }_{\mathrm{old}}
$$

The new increment of the encoder position is:

$$
\Delta \text { position }_{\text {new }}=\Delta \text { position }_{\mathrm{old}}
$$

The digital signal processor (DSP) calculates the PMSM speed and calculates how much the encoder position should change using Equations (7)-(11). If the encoder gives the wrong position, Equation (11) is not correct. Then, the correct encoder position is determined from the Equation (12).

\section{Materials and Methods}

To perform the planned experiments, a laboratory setup was prepared (Figure 5). 


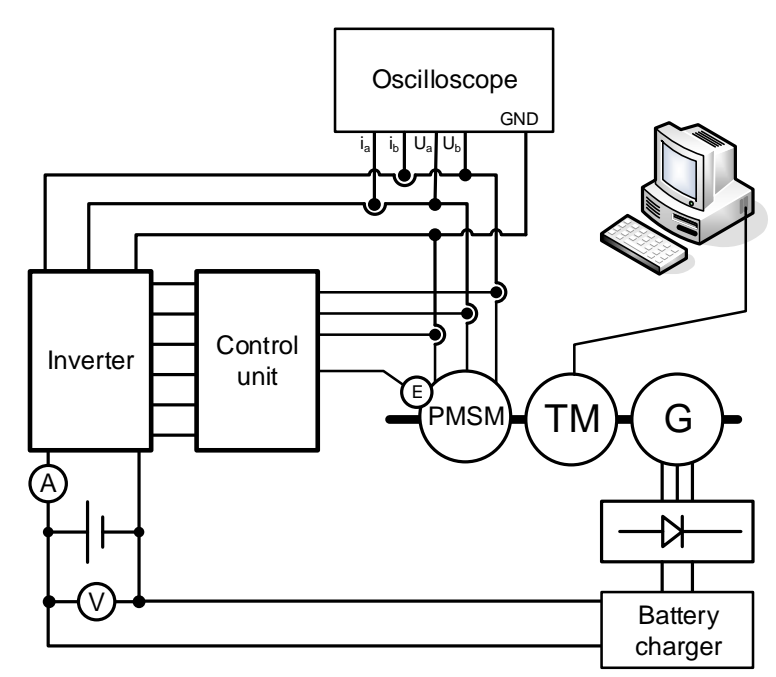

Figure 5. The laboratory setup for encoder testing of the drive with a PMSM.

The PMSM was linked to the torque measuring device (TM), generator (G), and encoder (E) by means of a common shaft. A three-phase 1-kW Brushless DC Motor (BLDC) motor worked as the generator. A DATAFLEX 22/20 (KTR, Germany) device placed on the torque-measuring shaft was used for torque sensing [23]. A detailed block diagram of the control unit is presented in Figure 6.

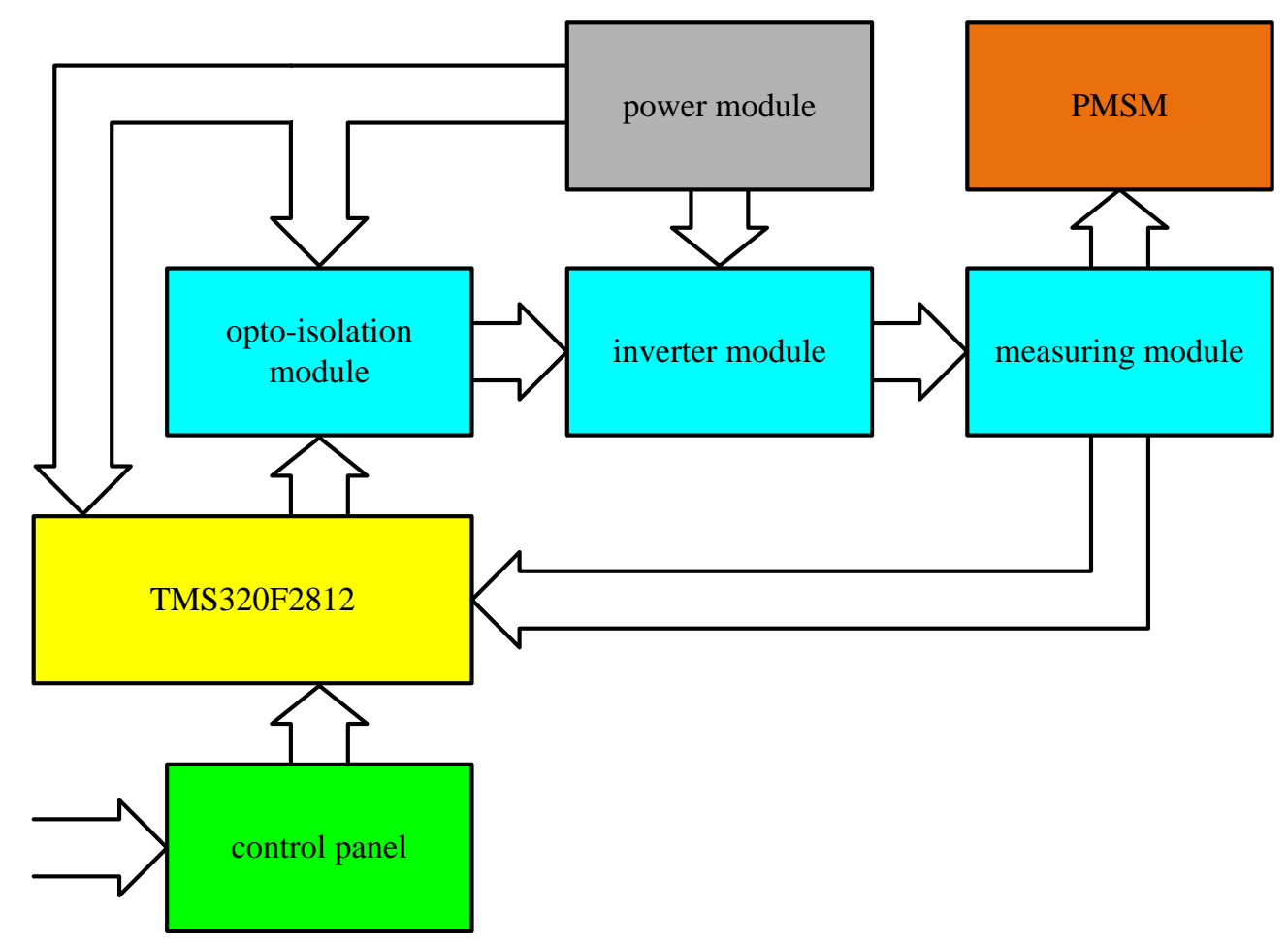

Figure 6. A detailed block diagram of the control unit.

The control unit consist of:

- Control panel;

- development board with TMS320F2812;

- opto-isolation module;

- inverter module;

- measuring module; 
- power module.

The parameters of the motor are summarized in Table 1.

Table 1. PMSM nameplate.

\begin{tabular}{cc}
\hline Parameter & Value \\
\hline Number of pole pairs & 3 \\
Rated voltage & $48 \mathrm{~V}$ \\
Rated current & $25 \mathrm{~A}$ \\
Rated speed & $1000 \mathrm{rpm}$ \\
Maximal current & $35 \mathrm{~A}$ \\
Torque & $6 \mathrm{Nm}$ \\
Rated power & $1 \mathrm{~kW}$ \\
\hline
\end{tabular}

The picture view of the experimental setup is presented in Figure 7.

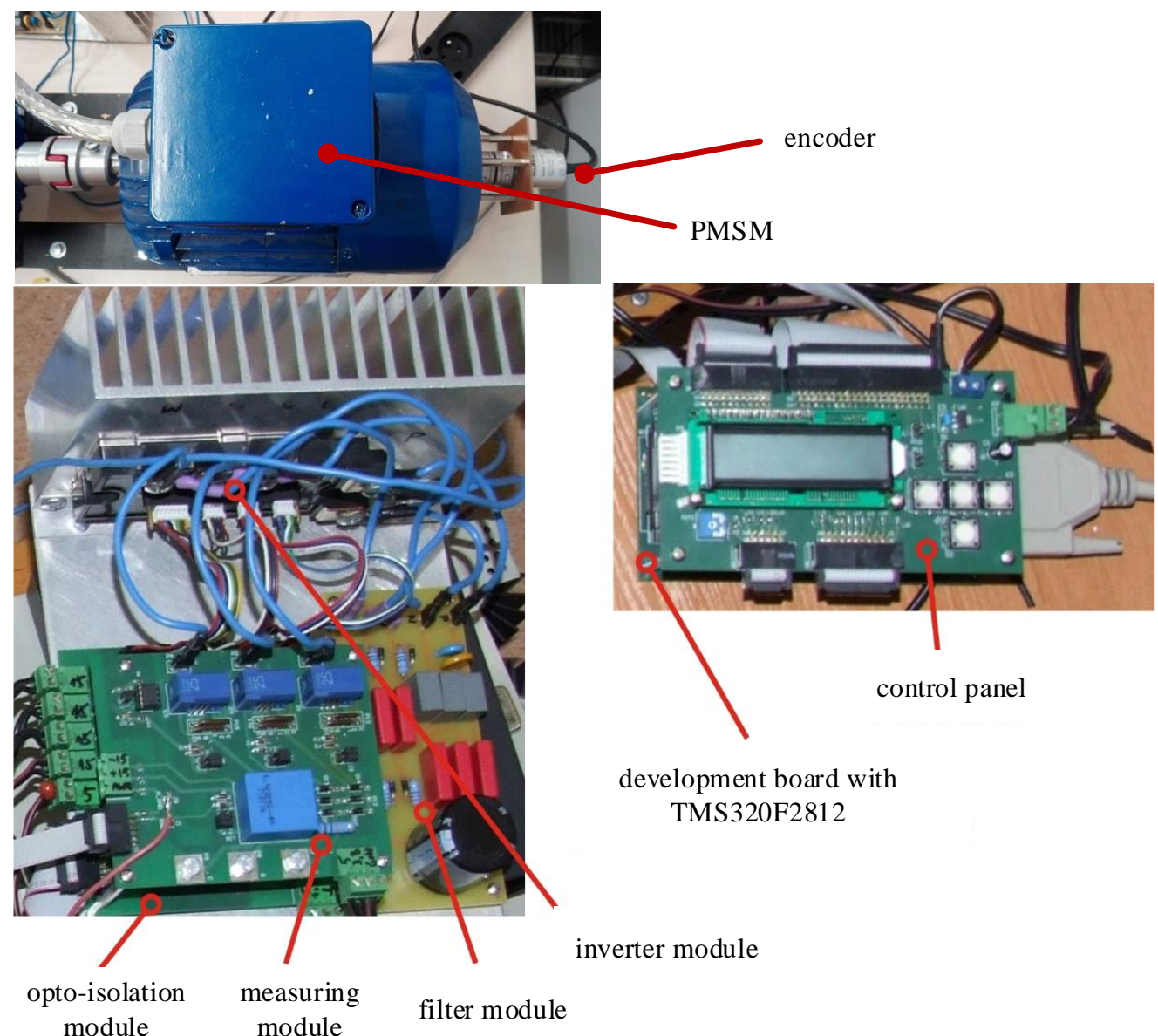

Figure 7. The picture view of the experimental setup.

\section{Results}

The laboratory setup presented in Figure 5 was used to perform a series of experiments. Measurements of the encoder were taken for changes of three parameters of the system:

- The PWM control frequency for the motor in the range of 4-20 kHz with increments of $4 \mathrm{kHz}$;

- the rotation speed for the motor at 300, 500, 750, and $1000 \mathrm{rpm}$;

- the load torque for the motor at 2,4 , and $6 \mathrm{Nm}$. 
The control algorithm was modified in order to count the errors of the absolute encoder for $24 \mathrm{~h}$. The number of errors was presented on the display. The measurements were taken for $24 \mathrm{~h}$ for each initially preset rotation speed, each frequency, and each load torque, so they covered the full range of the motor operation. The number of errors during the 24-h measurement was calculated as an average number of errors per hour. Then, the average number of encoder errors per hour for $2 \mathrm{Nm}$ was calculated (Table 2).

Table 2. The average number of encoder errors per hour for $2 \mathrm{Nm}$.

\begin{tabular}{cccccc}
\hline Speed & \multicolumn{5}{c}{ Frequency $f_{\text {PWM }}$} \\
\hline$\omega_{\text {rpm }}$ & $4 \mathrm{kHz}$ & $8 \mathrm{kHz}$ & $12 \mathrm{kHz}$ & $16 \mathrm{kHz}$ & $20 \mathrm{kHz}$ \\
300 & 1 & 1.2 & 1.3 & 0.9 & 1 \\
500 & 2.1 & 2.2 & 2 & 2.1 & 1.9 \\
750 & 3 & 3.2 & 3.1 & 3 & 3.1 \\
1000 & 4.1 & 4 & 4.2 & 4 & 3.9 \\
\hline
\end{tabular}

The encoder errors for $2 \mathrm{Nm}$ is shown in Figure 8. We can observe that the number of encoder errors depends little on the PWM frequency. The number of errors increased with the motor speed.

The encoder errors for $2 \mathrm{Nm}$

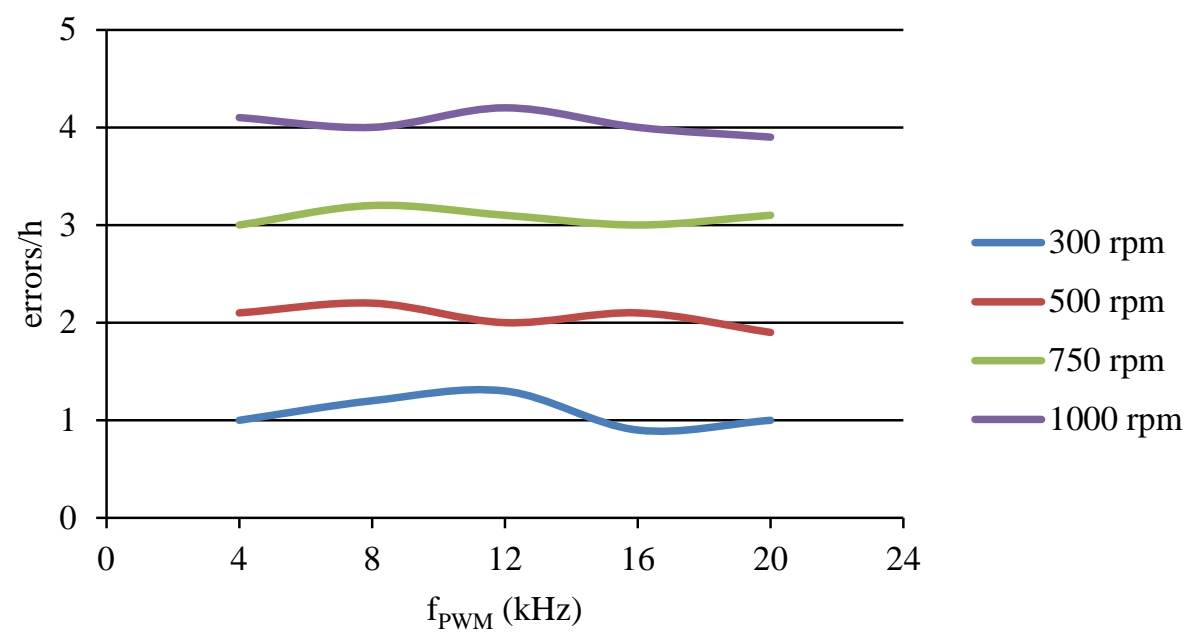

Figure 8. The encoder errors for $2 \mathrm{Nm}$.

The average number of encoder errors per hour for $4 \mathrm{Nm}$ is presented in Table 3.

Table 3. The average number of encoder errors per hour for $4 \mathrm{Nm}$.

\begin{tabular}{cccccc}
\hline Speed & \multicolumn{5}{c}{ Frequency $f_{\text {PWM }}$} \\
\hline$\omega_{\text {rpm }}$ & $4 \mathrm{kHz}$ & $8 \mathrm{kHz}$ & $12 \mathrm{kHz}$ & $16 \mathrm{kHz}$ & $20 \mathrm{kHz}$ \\
300 & 2 & 1.9 & 2.1 & 2 & 2.1 \\
500 & 4 & 3.9 & 3.9 & 4 & 4.1 \\
750 & 6 & 5.9 & 6 & 6.1 & 6.2 \\
1000 & 10.1 & 10.1 & 10 & 9.9 & 10 \\
\hline
\end{tabular}

The encoder errors for $4 \mathrm{Nm}$ is shown in Figure 9. We can observe that the number of encoder errors depends little on the PWM frequency. The number of errors increased with the motor speed. 
The encoder errors for $4 \mathrm{Nm}$

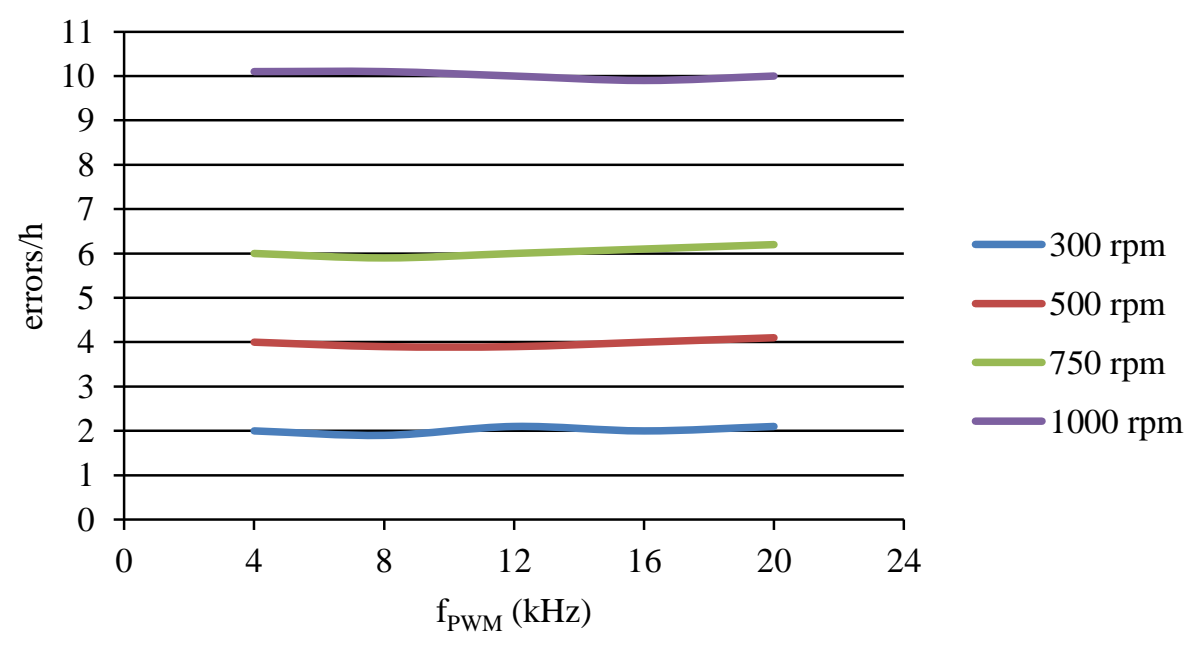

Figure 9. The encoder errors for $4 \mathrm{Nm}$.

The average number of encoder errors per hour for $6 \mathrm{Nm}$ was presented in Table 4.

Table 4. The average number of encoder errors per hour for $6 \mathrm{Nm}$.

\begin{tabular}{cccccc}
\hline Speed & \multicolumn{5}{c}{ Frequency $f_{\text {PWM }}$} \\
\hline$\omega_{\text {rpm }}$ & $4 \mathrm{kHz}$ & $8 \mathrm{kHz}$ & $12 \mathrm{kHz}$ & $16 \mathrm{kHz}$ & $20 \mathrm{kHz}$ \\
300 & 3 & 3.1 & 3.2 & 3 & 3.1 \\
500 & 6 & 5.9 & 6 & 6.1 & 6.2 \\
750 & 9.2 & 9.1 & 9 & 9.1 & 9 \\
1000 & 15 & 14.8 & 14.9 & 15 & 15 \\
\hline
\end{tabular}

The encoder errors for $6 \mathrm{Nm}$ is shown in Figure 10.

The encoder errors for $6 \mathrm{Nm}$

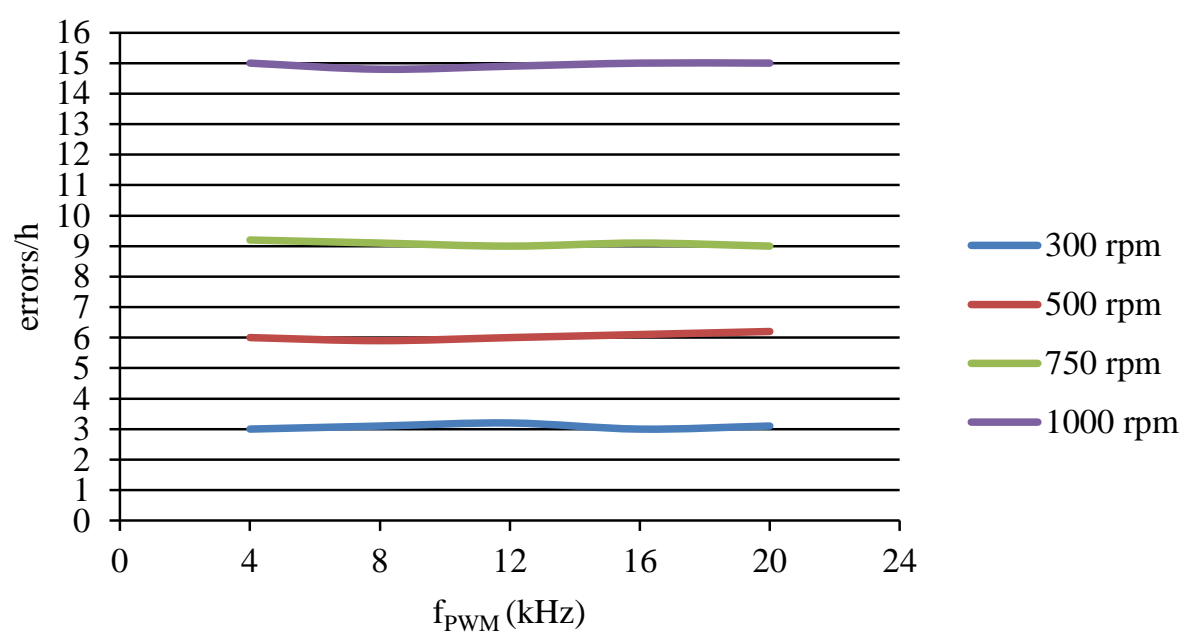

Figure 10. The encoder errors for $6 \mathrm{Nm}$.

We can observe that the number of encoder errors depends little on the PWM frequency. The number of errors increased with the motor speed. The encoder errors for $4 \mathrm{kHz}$ is shown in Figure 11. 
The encoder errors for $4 \mathrm{kHz}$

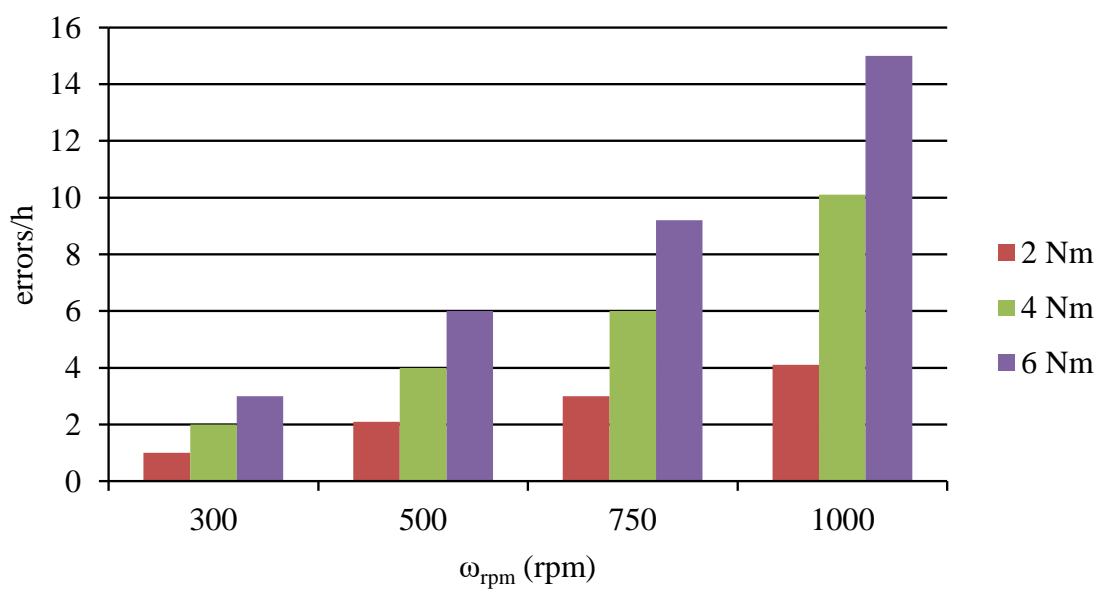

Figure 11. The encoder errors for $4 \mathrm{kHz}$.

The encoder errors for $8 \mathrm{kHz}$ is shown in Figure 12.

The encoder errors for $8 \mathrm{kHz}$

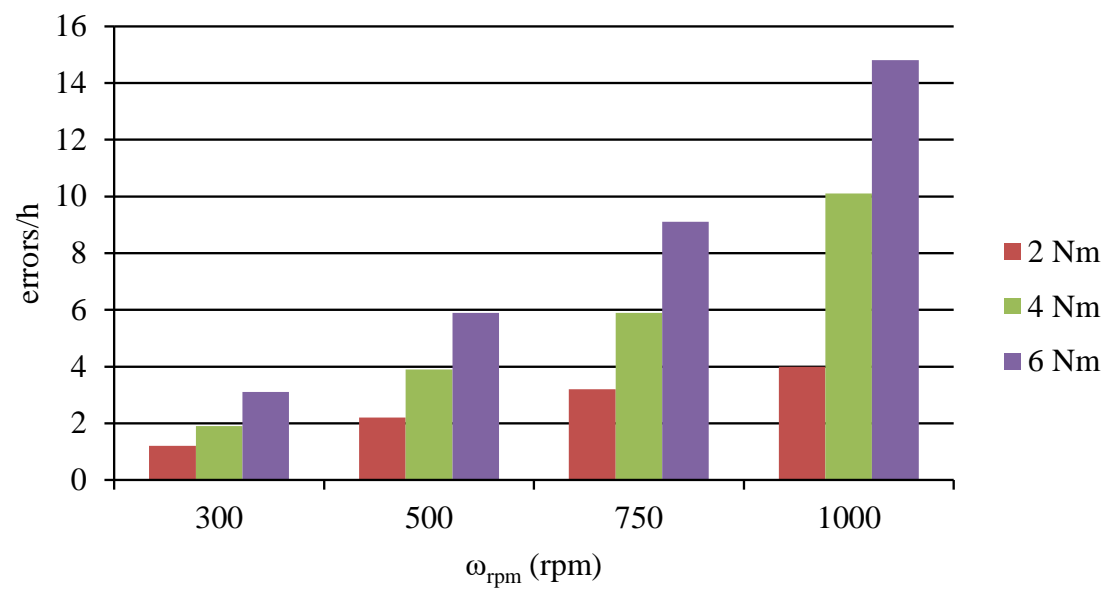

Figure 12. The encoder errors for $8 \mathrm{kHz}$.

The encoder errors for $12 \mathrm{kHz}$ is shown in Figure 13.

The encoder errors for $12 \mathrm{kHz}$

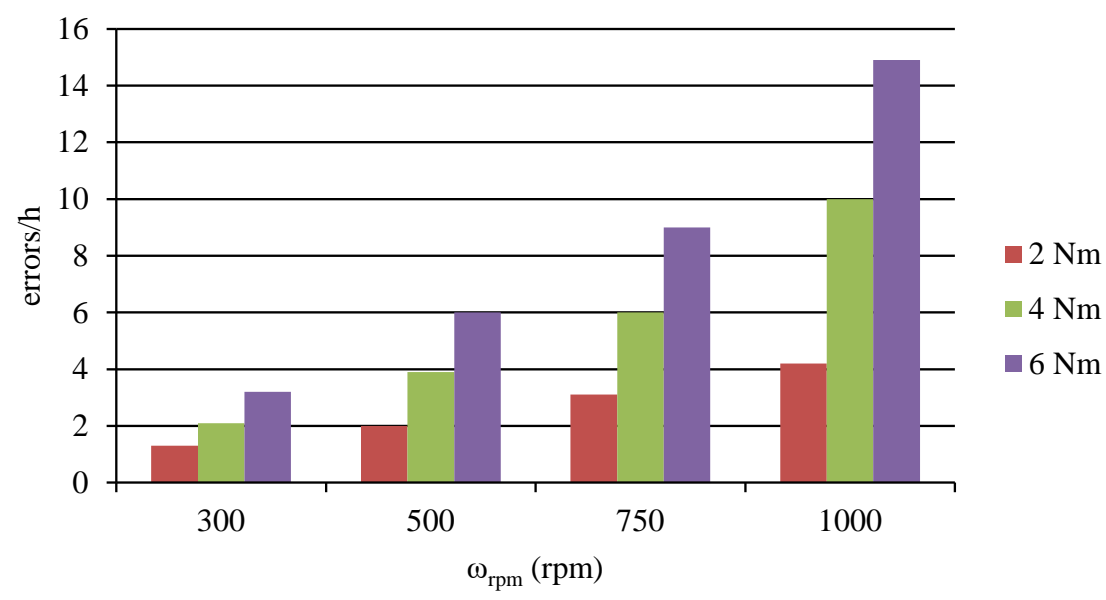

Figure 13. The encoder errors for $12 \mathrm{kHz}$. 
The encoder errors for $16 \mathrm{kHz}$ is shown in Figure 14.

The encoder errors for $16 \mathrm{kHz}$

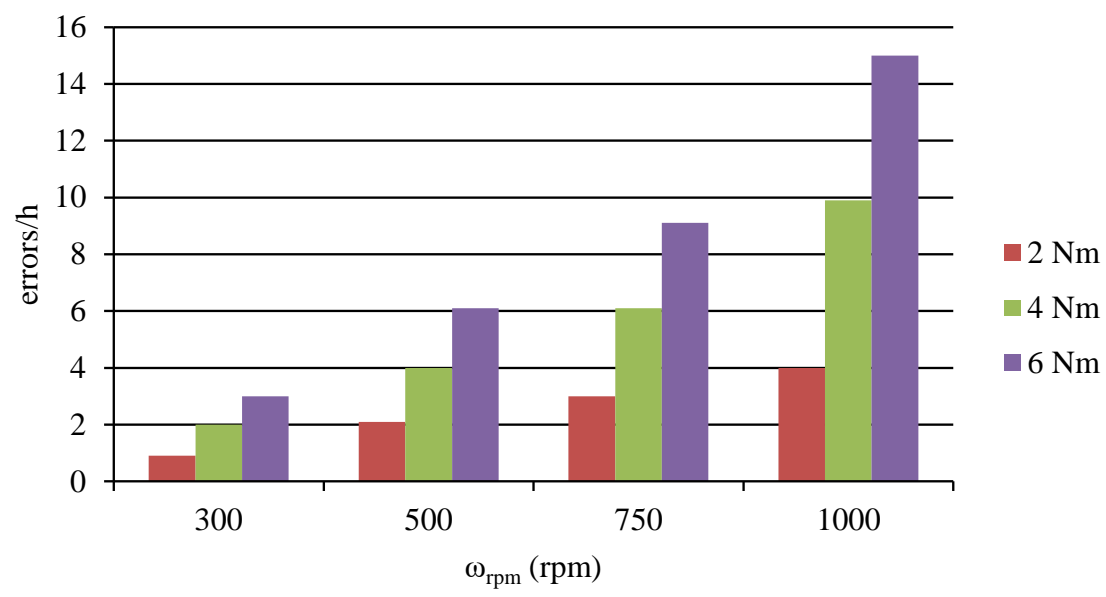

Figure 14. The encoder errors for $16 \mathrm{kHz}$.

The encoder errors for $20 \mathrm{kHz}$ is shown in Figure 15.

The encoder errors for $20 \mathrm{kHz}$

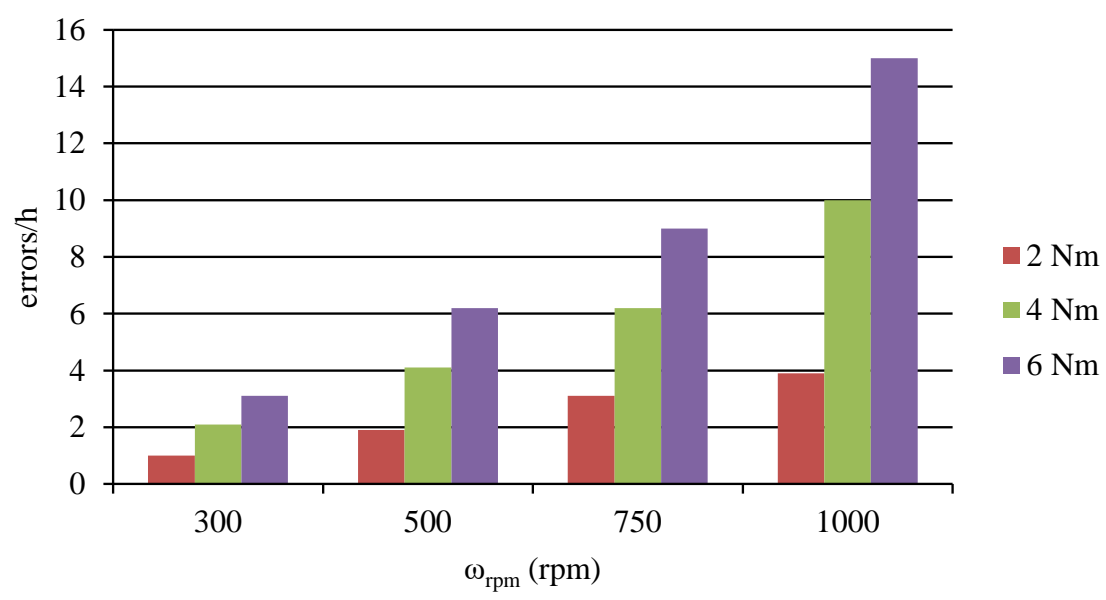

Figure 15. The encoder errors for $20 \mathrm{kHz}$.

We can observe that the number of encoder errors depends on the load torque for each frequency. The number of errors increased with the load torque for each frequency. Additionally, we can observe that the number of errors increased with the motor speed for each frequency.

\section{Discussion}

For the tested MAB28 absolute encoder, the average number of errors per hour was practically independent of frequency. A change in the PWM frequency had a weak effect on the number of encoder errors because it had little effect on the change of the PMSM motor current at constant load torque. The PMSM current was affected by the load torque. The number of encoder errors increased with increasing speed and with increasing load torque. Therefore, it can be concluded that an increase in rotational speed or an increase in load torque causes an increase in motor current. As the current consumed by the motor increases, the noise generated by the motor increases. This causes the encoder to operate under adverse conditions. This, in turn, causes the encoder to provide the wrong motor shaft position from time to time. For the correct operation of the drive system, correct the incorrect position of the drive shaft read from the encoder. 


\section{Conclusions}

The paper described how to deal with an encoder operating in the presence of interference, which, from time to time, returns to the wrong position of the motor shaft position. The investigations were carried out for the PMSM with a power of $1 \mathrm{~kW}$, a rated speed of $1000 \mathrm{rpm}$, and a rated torque of $6 \mathrm{Nm}$. The PWM frequency was varied within the range of 4 to $20 \mathrm{kHz}$ with increments of $4 \mathrm{kHz}$ with load torques of 2, 4, and $6 \mathrm{Nm}$, as well as rotation speeds of 300, 500, 750, and $1000 \mathrm{rpm}$.

Taking the control algorithm into account, the above dependencies can be protected against incorrect reading of the encoder position, which is a key matter in the vector control of the PMSM motor. The author experimentally verified how control of the motor's operation is adversely influenced if the above dependences are not taken into account. Controlling the motor without accounting for the aforementioned dependences leads to unstable operation characterized by temporary jerkiness and increased power consumption. It can be said that any encoder used to build the drive system will occasionally give the wrong position of the shaft. The number of these errors will depend on the encoder itself and the conditions under which it will work. Unfortunately, in practical applications, this important problem related to the reliability of the drive system is often overlooked.

The aim of this paper was to show that the PWM switching frequency does not affect the numbers of errors from encoder. The article also showed how to deal with the situation when the encoder gives the wrong position of the motor shaft. The original scientific contribution was to propose an original method for determining the correct position of the motor shaft. This method uses an absolute encoder that works in the presence of interference, which sometimes causes the encoder to return in the wrong position. Based on the PMSM speed, it is possible to determine what the encoder position should be during the next reading. Based on the position read from the encoder and the calculated one, it can be determined when the encoder gives the wrong position. If the position read from the encoder is incorrect, then the calculated encoder position should be used for further calculations of the FOC algorithm. The application of the proposed method is of practical importance because it can be used in industry.

Author Contributions: Conceptualization, T.R.; resources, T.R.; data curation, T.R.; writing—original draft preparation, T.R.; writing—review and editing, T.R.; visualization, T.R.; supervision, T.R.

Funding: This work was supported by the Ministry of Science and Higher Education funding for statutory activities.

Conflicts of Interest: The author declare no conflict of interest.

\section{References}

1. Pillay, P.; Krishnan, R. Modeling, simulation, and analysis of permanent-magnet motor-drives. I. The permanent-magnet synchronous motor drive. IEEE Trans. Ind. Appl. 1989, 25, 265-273. [CrossRef]

2. Czerwinski, R.; Rudnicki, T. Examination of electromagnetic noises and practical operations of a PMSM motor driven by a DSP and controlled by means of field oriented control. Elektron. ir Elektrotechnika 2014, 20, 46-50. [CrossRef]

3. Rudnicki, T.; Sikora, A.; Czerwinski, R.; Glinka, T. Impact of PWM control frequency on efficiency of drive with $1 \mathrm{~kW}$ permanent magnet synchronous motor. COMPEL Int. J. Comput. Math. Electr. Electron. Eng. 2018, 37, 307-318. [CrossRef]

4. Bourogaoui, M.; Jlassi, I.; Khojet El Khil, S.; Ben Attia Sethom, H. An effective encoder fault detection in PMSM drives at different speed ranges. In Proceedings of the IEEE 10th International Symposium on Diagnostics for Electrical Machines, Guarda, Portugal, 1-4 September 2015.

5. Kumar, P.; Kaushik, N.; Dahiya, S. Simulation of sensor less speed control of PMSM based on FOC method with MRAS adaptive speed estimator. In Proceedings of the 2013 Annual IEEE India Conference, Mumbai, India, 13-15 December 2013.

6. Kamel, T.; Abdelkader, D.; Said, B.; Padmanaban, S.; Iqbal, A. Extended Kalman Filter Based Sliding Mode Control of Parallel-Connected Two Five-Phase PMSM Drive System. Electronics 2018, 7, 14. [CrossRef] 
7. Chen, G.; Yang, S.; Hsu, Y.; Li, K. Position and Speed Estimation of Permanent Magnet Machine Sensorless Drive at High Speed Using an Improved Phase-Locked Loop. Energies 2017, 10, 1571. [CrossRef]

8. Wuri Harini, B.; Subiantoro, A.; Yusivar, F. Study of speed sensorless permanent magnet synchronous motor (PMSM) control problem due to braking during steady state condition. In Proceedings of the 2017 International Symposium on Electrical and Computer Engineering, Nusa Dua, Indonesia, 24-27 July 2017.

9. Sun, P.; Ge, Q.; Zhang, B.; Wang, X. Sensorless Control Technique of PMSM Based on RLS On-Line Parameter Identification. In Proceedings of the 2018 International Conference on Electrical Machines and Systems, Jeju, Korea, 7-10 October 2018.

10. Hind, D.; Li, C.; Sumner, M.; Gerada, C. Realising robust low speed sensorless PMSM control using current derivatives obtained from standard current sensors. In Proceedings of the 2017 IEEE International Electric Machines and Drives Conference, Miami, FL, USA, 21-24 May 2017.

11. Kim, H.; Son, J.; Lee, J. A High-Speed Sliding-Mode Observer for the Sensorless Speed Control of a PMSM. IEEE Trans. Ind. Electron. 2011, 58, 4069-4077.

12. Verrelli, C.; Bifaretti, S.; Carfagna, E.; Lidozzi, A.; Solero, L.; Crescimbini, F.; Di Benedetto, M. Speed Sensor Fault Tolerant PMSM Machines: From Position-Sensorless to Sensorless Control. IEEE Trans. Ind. Appl. 2019, 55, 3946-3954. [CrossRef]

13. Singh, S.; Tiwari, A.N.; Singh, S.N. Performance of Sensorless Method for PMSM Drive. In Proceedings of the 2018 IEEE India International Conference on Power Electronics, Jaipur, India, 13-15 December 2018.

14. Zhou, H.; Kuang, M.; Wu, J. A rotor position and speed estimation method for sensorless control of permanent magnetic synchronous motor. In Proceedings of the 2012 IEEE International Symposium on Power Electronics for Distributed Generation Systems, Aalborg, Denmark, 25-28 June 2012.

15. Sensored Field Oriented Control of 3-Phase Permanent Magnet Synchronous Motors Using TMS320F2837x. Available online: http://www.ti.com/lit/an/sprabz0/sprabz0.pdf (accessed on 20 June 2016).

16. Rudnicki, T.; Sikora, A.; Czerwinski, R.; Polok, D. Impact of PWM Control Frequency onto Efficiency of a 1 kW Permanent Magnet Synchronous Motor. Elektron. ir Elektrotechnika 2016, 22, 10-16. [CrossRef]

17. Berriri, H.; Naouar, M.W.; Slama-Belkhodja, I. Easy and Fast Sensor Fault Detection and Isolation Algorithm for Electrical Drives. IEEE Trans. Power Electron. 2012, 27, 490-499. [CrossRef]

18. Ramakrishnan, R.; Gebregergis, A.; Islam, M. Effect of Position Sensor Error on the Performance of PMSM Drives for Low Torque Ripple Applications. In Proceedings of the IEEE International Electric Machines and Drives Conference, Chicago, IL, USA, 12-15 May 2013; pp. 1166-1173.

19. Wu, S.T.; Chen, J.Y.; Wu, S.H. A Rotary Encoder With an Eccentrically Mounted Ring Magnet. IEEE Trans. Instrum. Meas. 2014, 63, 1907-1915. [CrossRef]

20. Zhang, H.F.; Liu, G. Rotor position estimation method of permanent magnet synchronous motor with absolute position calculation and simple deviation compensation strategies. Electron. Lett. 2017, 53, 1636-1637. [CrossRef]

21. TMS320F281x Digital Signal Processors. Available online: http://www.ti.com/lit/ds/symlink/tms320f2812.pdf (accessed on 20 July 2019).

22. Datenblatt für Winkelsensoren. Available online: https://www.megatron.de/kategorie/hall-effekt-singleturndrehgeber/download/93.html (accessed on 7 August 2017).

23. DATAFLEX. Available online: https://www.ktr.com/fileadmin/ktr/media/Manuals/49011en000000.pdf (accessed on 4 December 2017).

(C) 2019 by the author. Licensee MDPI, Basel, Switzerland. This article is an open access article distributed under the terms and conditions of the Creative Commons Attribution (CC BY) license (http://creativecommons.org/licenses/by/4.0/). 